\title{
One- or two-day intervals in conditioning regimens for allo-HCT affect chronic graft-versus-host disease, but not other clinical outcomes
}

\author{
Satoru Matsushima ${ }^{1}$, Ryoji Kobayashi ${ }^{2}$, Daiki Hori ${ }^{2}$, Masato Yanagi ${ }^{1}$, Hirozumi Sano ${ }^{1}$, and \\ Kunihiko Kobayashi ${ }^{1}$ \\ ${ }^{1}$ Sapporo Hokuyu Hospital \\ ${ }^{2}$ Sapporo Hokuyu hospital
}

February 7, 2022

\begin{abstract}
Background. One- or two-day intervals are generally inserted into scheduled conditioning regimens for allogeneic hematopoietic cell transplantation (HCT), primarily due to various social circumstances, such as unexpected natural adversities, abrupt deterioration of patient health, and delays in graft source arrival. We compared the clinical outcomes of patients with interrupted conditioning to those with ordinarily scheduled conditioning. Procedure. We retrospectively analyzed 83 patients (children and adolescents) with oncologic disease who underwent myeloablative conditioning with total body irradiation (TBI). Interruption of conditioning was defined as a regimen in which one or two vacant days (no chemotherapy drug administration or TBI) were added to the initially scheduled regimen. Results. Overall and event-free survival were similar between the scheduled conditioning group and the interrupted conditioning groups $(P=0.955, P=0.908$, respectively). Non-relapse mortality and relapse rates were similar between the groups $(P=0.923, P=0.946$, respectively). The engraftment rate was not affected by interruption $(P=1.000)$. In contrast, the incidence of grade II-IV acute graft-versus-host disease (GVHD) reached a marginally significant difference between the groups ( $31 \%$ vs. $11 \% ; P=0.083)$. Conditioning interruption was identified to be an independent risk factor for chronic GVHD by multivariate analysis (odds ratio: $3.72 ; 95 \%$ CI: $1.04-13.3 ; P=0.043$ ). Conclusion. Apart from the incidence of chronic GVHD, clinical outcomes were not affected by one- or two-day intervals during conditioning.
\end{abstract}

\section{Introduction}

Many studies of conditioning regimens for hematopoietic cell transplantation (HCT) have been conducted over the last few decades, and various regimens are now available. Furthermore, conditioning intensity and its effects on transplantation outcomes have been well researched, which has led to decreased transplantationassociated morbidity and mortality [1-4]. Several studies have revealed the equivalence of a reduced intensity regimen, in terms of overall survival (OS) and event-free survival (EFS), in comparison to a conventional myeloablative conditioning (MAC) regimen [5-8]. Additionally, the incidence of graft-versus-host disease (GVHD) is known to be affected by conditioning intensity [9-13]. However, there are no reports concerning the relationship between clinical outcomes and differences in scheduling strategies for conditioning regimens consisting of equivalent doses and types of chemotherapeutic agents and total body irradiation (TBI).

Conditioning regimens for HCT should be performed according to the usual standards and timescales. Nonetheless, one- or two-day intervals are occasionally enacted during the conditioning period because of hospital closure, predetermined dates of unrelated donor HCT, or simultaneous HCTs for multiple patients. Furthermore, unexpected situations requiring HCT postponement can occur. Therefore, it is important to 
identify potential negative effects of $\mathrm{HCT}$ conditioning interruptions on clinical outcomes. We evaluated this hypothesis in pediatric patients with oncologic diseases undergoing HCT after MAC.

\section{Subjects and Methods}

\section{Patient eligibility}

A total of 83 children and adolescents with a malignant disease underwent allogeneic hematopoietic cell transplantation (allo-HCT) after MAC with TBI at Sapporo Hokuyu Hospital between October 1994 and July 2018. All of the patients were enrolled in this study, and their clinical data were retrospectively evaluated by December $31^{\text {st }}, 2019$. All enrolled patients were $<20$ years old, and their diagnoses of hematologic malignancies were: acute lymphoblastic leukemia, acute myeloid leukemia, chronic myeloid leukemia, juvenile myelomonocytic leukemia, myelodysplastic syndromes, and non-Hodgkin lymphoma. Additionally, the diagnoses for solid tumors included neuroblastoma and hepatoblastoma. Ninety-two percent of the diagnoses were hematologic malignant disease. The enrolled patients received HCT from related or unrelated donors at either complete remission or incomplete remission.

This study was conducted according to the Declaration of Helsinki and was approved by the Ethics Committee at Sapporo Hokuyu Hospital, Sapporo, Japan.

\section{Transplant details and GVHD prophylaxis}

Both donor types (related or unrelated) contained matched or mismatched grafts. Graft sources were derived from bone marrow, peripheral blood, or cord blood. All conditioning regimens utilized for the eligible patients involved MAC with 12 or 13.2 Gy of TBI. TBI was administered to the patients in six fractions (two fractions per day). Different GVHD prophylaxis was adopted according to the administered graft source. GVHD prophylaxis for cord blood transplantation (CBT) consists of cyclosporin (CSA) and methylprednisolone. Most GVHD prophylaxis for HCT from the graft of a related donor consisted of CSA and methotrexate (MTX). Prophylaxis for HCT from a graft of an unrelated donor consisted of tacrolimus and MTX.

\section{Study endpoints and definitions}

The objective of this study was to clarify the impact of conditioning interruptions on clinical outcomes after HCT. Clinical endpoints included OS, EFS, non-relapse mortality (NRM), relapse rate (RR), engraftment, and acute or chronic GVHD incidence. The incidences of veno-occlusive disease/sinusoidal obstruction syndrome (VOD/SOS), thrombotic microangiopathy (TMA), and interstitial pneumonia were evaluated as transplantation-associated complications. EFS was defined as survival without death due to any cause, or survival without recurrence of the primary disease. NRM was defined as death for any reason other than primary disease relapse or progression, and $\mathrm{RR}$ was estimated by considering death without prior relapse as a competing event. The engraftment definition was attainment of $>0.5 \times 10^{9} / \mathrm{L}$ absolute neutrophil count for three consecutive days. The diagnosis and grading of acute graft-versus-host disease (aGVHD) were implemented based on the manifestation of skin, intestine, and liver symptoms arising within 100 days after HCT. Other causes for the symptoms were excluded. The aGVHD grading was conducted according to the consensus conference on aGVHD grading in 1994 [14]. The diagnosis of chronic graft-versus-host disease (cGVHD) was also made using the signs and symptoms of cGVHD occurring beyond 100 days after HCT. The distinctive symptoms of cGVHD employed were similar to those specified in the National Institute of Health criteria for cGVHD in 2005 [15].

Interruption of conditioning was defined as a regimen in which one or two vacant days (no chemotherapy drug administration or TBI) were added to the initially scheduled regimen. Examples of interrupted conditioning are shown in Figure 1.

\section{Statistical analysis}

Fisher's exact test was used for categorical variables. The Mann-Whitney U test was used for continuous variables such as the baseline characteristics and clinical endpoints of the patients. These tests were used to evaluate differences between the scheduled and interrupted groups. OS and EFS were estimated using 
the Kaplan-Meier method and compared with the log-rank test. The comparison of NRM and cumulative incidence of relapse were evaluated using Gray's test.

A multivariate logistic regression model was created to identify the statistically significant clinical variables contributing to the incidence of cGVHD. Categorical variables with $P$-values $<0.1$ in the univariate analysis for the factors causing cGVHD were entered into the model. The categorical variables were sequentially eliminated in a stepwise backward fashion. Factors with a significance level of $<0.05$ were retained in the final model. A $P$-value of [?] 0.05 was considered statistically significant. All statistical analyses were performed with Easy R (EZR), a graphical user interface for R (The R Foundation for Statistical Computing). EZR is a modified version of the $\mathrm{T}$ commander designed to add statistical functions frequently used in biostatistics $[16]$.

\section{Results}

\section{Patient characteristics}

Baseline patient characteristics in the two cohorts are summarized in Table 1. Among the 83 analyzed patients, 64 underwent the ordinarily scheduled conditioning regimen and 19 had their conditioning regimen interrupted. The mean number of interrupted days was 1.4 days, and the interval during TBI was set for eight out of 19 patients with interrupted conditioning. The median age at HCT in the scheduled group was 9.5 years old (a range of 1.5-19.9), and 10.9 years old (range, 3.5-19.5) in the interrupted group.

No significant differences between the groups were detected in the stage at transplantation $(P=0.721)$. TBI combined with etoposide and cyclophosphamide was the most frequently used regimen in this study. The type of conditioning regimen adopted and the drug used in conditioning were also not significantly different between the two groups ( $P=0.537$ and $P=0.803$, respectively).

Regarding transplantation status, cord blood grafts were occasionally utilized. This procedure was mostly used for unrelated donor grafts and the minority of HLA-matched grafts in this study. The type of graft source was statistically well matched between the two groups $(P=0.660)$. Regarding the drugs used for GVHD prophylaxis, tacrolimus was used more frequently in the interrupted group than in the scheduled group $(P=0.022)$.

\section{Transplantation outcomes}

The median administered $\mathrm{CD} 34^{+}$cell dose was the same between the scheduled and interrupted groups $\left(2.2 \times 10^{6} / \mathrm{kg}\right.$ and $2.0 \times 10^{6} / \mathrm{kg}$ for the scheduled and interrupted groups, respectively; $\left.P=0.845\right)$. Engraftment was achieved in most enrolled patients $(92 \%$ and $95 \%$ of the scheduled and interrupted groups, respectively; $P=1.000)$. The median days until engraftment was also not significantly different between the two groups (18 days vs. 19 days; $P=0.976$ ). The 5-year OS and EFS in the interrupted group were the same as the scheduled group ( $53 \%$ vs. $52 \% ; P=0.955$; and $47 \%$ vs. $45 \% ; P=0.908$, respectively). These results are shown in Figure 2. Additionally, the 5-year NRM and RR were similar between the scheduled and interrupted groups ( $16 \%$ vs. $16 \% ; P=0.923$; and $42 \%$ vs. $44 \% ; P=0.946$, respectively). The incidence of transplantation-associated complications was not different between the two groups (VOD/SOS; $6.3 \%$ vs. $5.3 \%, P=1.000$, TMA; $4.7 \%$ vs. $0.0 \%, P=1.000$, interstitial pneumonia; $9.4 \%$ vs. $5.3 \%, P=1.000)$.

The incidences of acute and chronic GVHD in the two cohorts are summarized in Table 2. Overall, aGVHD was more often identified in the scheduled group than in the interrupted group, although the differences were not statistically significant. The incidence of aGVHD in grades I-IV in the scheduled and interrupted groups was $42 \%$ and $26 \%$, respectively $(P=0.286)$. Moreover, there was a trend toward a higher incidence of grades II-IV aGVHD in the scheduled group compared to the interrupted group $(31 \%$ vs. $11 \% ; P=$ 0.083). The incidence of aGVHD in grades III-IV was also higher in the scheduled group than in the interrupted group (19\% vs. $5 \% ; P=0.280$ ). Furthermore, the group with interrupted conditioning showed a marginally significant tendency toward a higher incidence of cGVHD than the scheduled conditioning group ( $42 \%$ vs. $19 \% ; P=0.063$ ). The categorical variables entered into the multivariate model were age of [?] 10 years, female, interruption of conditioning, use of cyclosporin, and tacrolimus. Consequently, interrupted 
conditioning for allo-HCT was confirmed by the multivariate analysis to be an independent risk factor for cGVHD (odds ratio: 3.72; 95\% CI: 1.04-13.3; $P=0.043$ ). Additionally, age of [?] 10 years and female gender were also identified as significant risk factors for cGVHD. These results and the results of univariate analysis for cGVHD are shown in Tables 3 and 4.

\section{Discussion}

One or two non-treatment days are occasionally added to initial HCT conditioning regimens due to various social circumstances, such as unexpected natural adversities, abrupt deterioration of patient health, and delays in graft source arrival. Consequently, concerns pertaining to the impact of interrupted conditioning on clinical outcomes after $\mathrm{HCT}$ have arisen as a consequential issue.

Remarkably, in our cohorts, it was shown that the clinical outcome after HCT was not affected by conditioning interruption. The 5-year OS and EFS were the same between the groups with or without interruption of conditioning. Moreover, the cumulative incidences of relapse and NRM were not significantly different between the groups. We also found that engraftment was not affected by a few-day interruption of conditioning. In contrast, marginal differences were observed in GVHD incidence between the groups. In this study, grade II-IV aGVHD was observed less often in the interrupted conditioning group, with marginal significance. However, a significantly higher incidence of cGVHD was observed in the interrupted conditioning group, as demonstrated by the multivariate model.

Generally, it is presumed that adding one- or two-day intervals into the conditioning regimen leads to the attenuation of conditioning intensity. It is also assumed that the non-treatment days could allow malignant cells to recover from the toxicity caused by chemotherapeutic agents or TBI. However, it is noted that the capacity for toxicity recovery is likely to be decreased more in tumor cells than in normal cells and is expected to be heterogeneous in each type of cancer cell [17-20]. Moreover, it is not known if the repair capacity of tumor cells recovers in a short period of a few days [21-24]. Thus, it is challenging to determine whether the interrupted conditioning decreases anti-tumor effects. Herein, potential negative impacts of conditioning interruption on clinical outcomes, other than the incidence of cGVHD, were assessed.

It is conceivable that normal tissue would benefit from conditioning interruption because of the possibility of recovering from tissue damage and inflammation before HCT $[17,25]$. However, there were no differences in a transplantation-associated complications between the two groups in the present study.

Regarding aGVHD, differences in tissue damage severity and donor chimerism formation due to interrupted conditioning could be a plausible explanation for the observed lower incidence of aGVHD in the interrupted group [26-30]. It has been reported that patients with mixed chimerism experienced aGVHD less often than patients who attained donor chimerism early after HCT [31-32]. Furthermore, it has been noted that cGVHD development was delayed and of less severity when the state of mixed chimerism was prolonged [33]. Moreover, a study identified reduced-intensity conditioning as a risk factor for cGVHD [34]. In relation to this, it has been reported that a mixed chimerism state was related to high levels of pathogenic IgG autoantibody and the development of cGVHD-like lesions in a murine model. This result was explained by the persistence of host B cells after HCT [35]. Thus, changes in timing or state of donor chimerism caused by interruption of conditioning might affect the present results regarding aGVHD and cGVHD incidences between the scheduled and interrupted conditioning groups.

This study is limited by its retrospective nature and small sample size, especially the small number of patients in the interrupted conditioning group. This limitation did not permit sub-analysis stratified by graft source or donor source. Additionally, the present results would not apply to other conditioning regimens because the narrow study population only contained pediatric patients who received MAC with TBI.

In conclusion, one- or two-day interruptions of HCT conditioning appeared to have no effect on OS and EFS. However, interrupted conditioning could affect the incidence of GVHD and be a risk factor for cGVHD. The relationship between a few-day interval during conditioning and GVHD development and its mechanism requires further elucidation in future studies. 


\section{Conflict of interest statement}

The authors have no conflicts of interest to declare.

\section{Data availability statement}

The data that support the findings of this study are available from the corresponding author upon reasonable request.

\section{References}

1. Gooley TA, Chien JW, Pergam SA, Hingorani S, Sorror ML, Boeckh M, Martin PJ, Sandmaier BM, Marr KA, Appelbaum FR, Storb R, McDonald GB. Reduced mortality after allogeneic hematopoieticcell transplantation. N Engl J Med. 2010 Nov 25;363(22):2091-2101.

2. Svenberg P, Remberger M, Uzunel M, Mattsson J, Gustafsson B, Fjaertoft G, Sundin M, Winiarski J, Ringden O. Improved overall survival for pediatric patients undergoing allogeneic hematopoietic stem cell transplantation - A comparison of the last two decades. Pediatr Transplant. 2016 Aug;20(5):667674.

3. Paix A, Antoni D, Waissi W, Ledoux MP, Bilger K, Fornecker L, Noel G. Total body irradiation in allogeneic bone marrow transplantation conditioning regimens: A review. Crit Rev Oncol Hematol. 2018 Mar;123:138-148.

4. McDonald GB, Slattery JT, Bouvier ME, Ren S, Batchelder AL, Kalhorn TF, Schoch HG, Anasetti C, Gooley T. Cyclophosphamide metabolism, liver toxicity, and mortality following hematopoietic stem cell transplantation. Blood. 2003 Mar 1;101(5):2043-2048.

5. Ishida H, Adachi S, Hasegawa D, Okamoto Y, Goto H, Inagaki J, Inoue M, Koh K, Yabe H, Kawa K, Kato K, Atsuta Y, Kudo K. Comparison of a fludarabine and melphalan combination-based reduced toxicity conditioning with myeloablative conditioning by radiation and/or busulfan in acute myeloid leukemia in Japanese children and adolescents. Pediatr Blood Cancer. 2015 May;62(5):883-889.

6. Harada K, Tachibana T, Ohashi K, Ozawa Y, Sawa M, Kondo T, Ishikawa J, Onizuka M, Imada K, Fujisaki T, Tanaka J, Fukuda T, Atsuta Y, Kako S. The effect of melphalan dose and total body irradiation as reduced-intensity conditioning for acute lymphoblastic leukemia patients undergoing allogeneic stem cell transplantation. Leuk Lymphoma. 2019 Dec;60(14):3521-3528.

7. Bitan M, He W, Zhang MJ, Abdel-Azim H, Ayas MF, Bielorai B, Carpenter PA, Cairo MS, Diaz MA, Horan JT, Jodele S, Kitko CL, Schultz KR, Kletzel M, Kasow KA, Lehmann LE, Mehta PA, Shah N, Pulsipher MA, Prestidge T, Seber A, Shenoy S, Woolfrey AE, Yu LC, Davies SM. Transplantation for children with acute myeloid leukemia: a comparison of outcomes with reduced intensity and myeloablative regimens. Blood. 2014 Mar 6;123(10):1615-1620.

8. Satwani P, Cooper N, Rao K, Veys P, Amrolia P. Reduced intensity conditioning and allogeneic stem cell transplantation in childhood malignant and nonmalignant diseases. Bone Marrow Transplant. 2008 Jan;41(2):173-182.

9. Couriel DR, Saliba RM, Giralt S, Khouri I, Andersson B, de Lima M, Hosing C, Anderlini P, Donato M, Cleary K, Gajewski J, Neumann J, Ippoliti C, Rondon G, Cohen A, Champlin R. Acute and chronic graft-versus-host disease after ablative and nonmyeloablative conditioning for allogeneic hematopoietic transplantation. Biol Blood Marrow Transplant. 2004 Mar;10(3):178-185.

10. Perez-Simon JA, Diez-Campelo M, Martino R, Brunet S, Urbano A, Caballero MD, de Leon A, Valcarcel D, Carreras E, del Canizo MC, Lopez-Fidalgo J, Sierra J, San Miguel JF. Influence of the intensity of the conditioning regimen on the characteristics of acute and chronic graft-versus-host disease after allogeneic transplantation. Br J Haematol. 2005 Aug;130(3):394-403.

11. Oran B, Wagner JE, DeFor TE, Weisdorf DJ, Brunstein CG. Effect of conditioning regimen intensity on acute myeloid leukemia outcomes after umbilical cord blood transplantation. Biol Blood Marrow Transplant. 2011 Sep;17(9):1327-1334.

12. Salas MQ, Chen S, Lam W, Pasic I, Gerbitz A, Michelis FV, Kim DDH, Al-Shaibani Z, Lipton JH, Mattsson J, Kumar R, Viswabandya A, Law AD. Less Is More: Superior Graft-versus-Host DiseaseFree/Relapse-Free Survival with Reduced-Intensity Conditioning and Dual T Cell Depletion in Acute 
Myelogenous Leukemia. Biol Blood Marrow Transplant. 2020 Aug;26(8):1511-1519.

13. Terwey TH, Vega-Ruiz A, Hemmati PG, Martus P, Dietz E, le Coutre P, Massenkeil G, Dorken B, Arnold R. NIH-defined graft-versus-host disease after reduced intensity or myeloablative conditioning in patients with acute myeloid leukemia. Leukemia. 2012 Mar;26(3):536-542.

14. Przepiorka D, Weisdorf D, Martin P, Klingemann HG, Beatty P, Hows J, Thomas ED. 1994 Consensus Conference on Acute GVHD Grading. Bone Marrow Transplant. 1995 Jun;15(6):825-828.

15. Filipovich AH, Weisdorf D, Pavletic S, Socie G, Wingard JR, Lee SJ, Martin P, Chien J, Przepiorka D, Couriel D, Cowen EW, Dinndorf P, Farrell A, Hartzman R, Henslee-Downey J, Jacobsohn D, McDonald G, Mittleman B, Rizzo JD, Robinson M, Schubert M, Schultz K, Shulman H, Turner M, Vogelsang G, Flowers ME. National Institutes of Health consensus development project on criteria for clinical trials in chronic graft-versus-host disease: I. Diagnosis and staging working group report. Biol Blood Marrow Transplant. 2005 Dec;11(12):945-956.

16. Kanda Y. Investigation of the freely available easy-to-use software 'EZR' for medical statistics. Bone Marrow Transplant. 2013 Mar;48(3):452-458.

17. Peters LJ, Withers HR, Cundiff JH, Dicke KA. Radiobiological considerations in the use of total-body irradiation for bone-marrow transplantation. Radiology. 1979 Apr;131(1):243-247.

18. Wheldon TE. The radiobiological basis of total body irradiation. Br J Radiol. 1997 Dec;70(840):12041207.

19. Uckun FM, Jaszcz W, Chandan-Langlie M, Waddick KG, Gajl-Peczalska K, Song CW. Intrinsic radiation resistance of primary clonogenic blasts from children with newly diagnosed B-cell precursor acute lymphoblastic leukemia. J Clin Invest. 1993 Mar;91(3):1044-1051.

20. Dutreix J, Wambersie A, Loirette M, Boisserie G. Time factors in total body irradiation. Pathol Biol (Paris). 1979 Jun;27(6):365-9.

21. Uckun FM, Chandan-Langlie M, Jaszcz W, Obuz V, Waddick K, Song CW. Radiation damage repair capacity of primary clonogenic blasts in acute lymphoblastic leukemia. Cancer Res. 1993 Mar 15;53(6):1431-1436.

22. Pearson AE, Steel GG. Chemotherapy in combination with pelvic irradiation: a time-dependence study in mice. Radiother Oncol. 1984 Jun;2(1):49-55.

23. Collis CH, Steel GG. Lung damage in mice from cyclophosphamide and thoracic irradiation: the effect of timing. Int J Radiat Oncol Biol Phys. 1983 May;9(5):685-9.

24. Parkins CS, Whitsed CA, Fowler JF. Repair kinetics in mouse lung after multiple X-ray fractions per day. Int J Radiat Biol. 1988 Sep;54(3):429-443.

25. Van Rongen E, Kuijpers WC, Madhuizen HT. Fractionation effects and repair kinetics in rat kidney. Int J Radiat Oncol Biol Phys. 1990 May;18(5):1093-1106.

26. Clift RA, Buckner CD, Appelbaum FR, Bearman SI, Petersen FB, Fisher LD, Anasetti C, Beatty P, Bensinger WI, Doney K, et al. Allogeneic marrow transplantation in patients with acute myeloid leukemia in first remission: a randomized trial of two irradiation regimens. Blood. 1990 Nov $1 ; 76(9): 1867-1871$.

27. Nakasone H, Fukuda T, Kanda J, Mori T, Yano S, Kobayashi T, Miyamura K, Eto T, Kanamori H, Iwato K, Uchida N, Mori S, Nagamura-Inoue T, Ichinohe T, Atsuta Y, Teshima T, Murata M; GVHD working group of the Japan Society of Hematopoietic Cell Transplantation. Impact of conditioning intensity and TBI on acute GVHD after hematopoietic cell transplantation. Bone Marrow Transplant. 2015 Apr;50(4):559-565.

28. Harris AC, Ferrara JL, Levine JE. Advances in predicting acute GVHD. Br J Haematol. 2013 Feb;160(3):288-302.

29. Baron F, Baker JE, Storb R, Gooley TA, Sandmaier BM, Maris MB, Maloney DG, Heimfeld S, Oparin D, Zellmer E, Radich JP, Grumet FC, Blume KG, Chauncey TR, Little MT. Kinetics of engraftment in patients with hematologic malignancies given allogeneic hematopoietic cell transplantation after nonmyeloablative conditioning. Blood. 2004 Oct 15;104(8):2254-2262.

30. Kassim AA, Chinratanalab W, Ferrara JL, Mineishi S. Reduced-intensity allogeneic hematopoietic stem cell transplantation for acute leukemias: 'what is the best recipe?'. Bone Marrow Transplant. 
2005 Oct;36(7):565-574.

31. Perez-Simon JA, Caballero D, Diez-Campelo M, Lopez-Perez R, Mateos G, Canizo C, Vazquez L, Vidriales B, Mateos MV, Gonzalez M, San Miguel JF. Chimerism and minimal residual disease monitoring after reduced intensity conditioning (RIC) allogeneic transplantation. Leukemia. 2002 Aug;16(8):14231431.

32. Elkaim E, Picard C, Galambrun C, Barlogis V, Loundou A, Curtillet C, Oudin C, Thuret I, Chambost H, Michel G. Peripheral blood cells chimerism after unrelated cord blood transplantation in children: kinetics, predictive factors and impact on post-transplant outcome. Br J Haematol. 2014 Aug;166(4):557-565.

33. Balon J, Hałaburda K, Bieniaszewska M, Reichert M, Bieniaszewski L, Piekarska A, Pawłowski R, Hellmann A. Early complete donor hematopoietic chimerism in peripheral blood indicates the risk of extensive graft-versus-host disease. Bone Marrow Transplant. 2005 Jun;35(11):1083-1088.

34. Afram G, Simón JAP, Remberger M, Caballero-Velázquez T, Martino R, Piñana JL, Ringden O, Esquirol A, Lopez-Corral L, Garcia I, López-Godino O, Sierra J, Caballero D, Ljungman P, Vazquez L, Hägglund H. Reduced intensity conditioning increases risk of severe cGVHD: identification of risk factors for cGVHD in a multicenter setting. Med Oncol. 2018 Apr 25;35(6):79.

35. Perruche S, Marandin A, Kleinclauss F, Angonin R, Fresnay S, Baron MH, Tiberghien P, Saas P. Association of mixed hematopoietic chimerism with elevated circulating autoantibodies and chronic graft-versus-host disease occurrence. Transplantation. 2006 Feb 27;81(4):573-582.

\section{Legends}

Figure 1.

Examples of interrupted conditioning regimens. Normal conditioning regimen (a). Interrupted conditioning regimens $(b, c)$.

Figure 2 .

Comparison of 5-year overall survival (OS) and event-free survival (EFS) between scheduled and interrupted conditioning groups. 5-year OS is 52\% in the scheduled conditioning group and $53 \%$ in the interrupted conditioning group $(P=0.955)$. 5 -year EFS is $45 \%$ in the scheduled conditioning group and $47 \%$ in the interrupted conditioning group $(P=0.908)$.

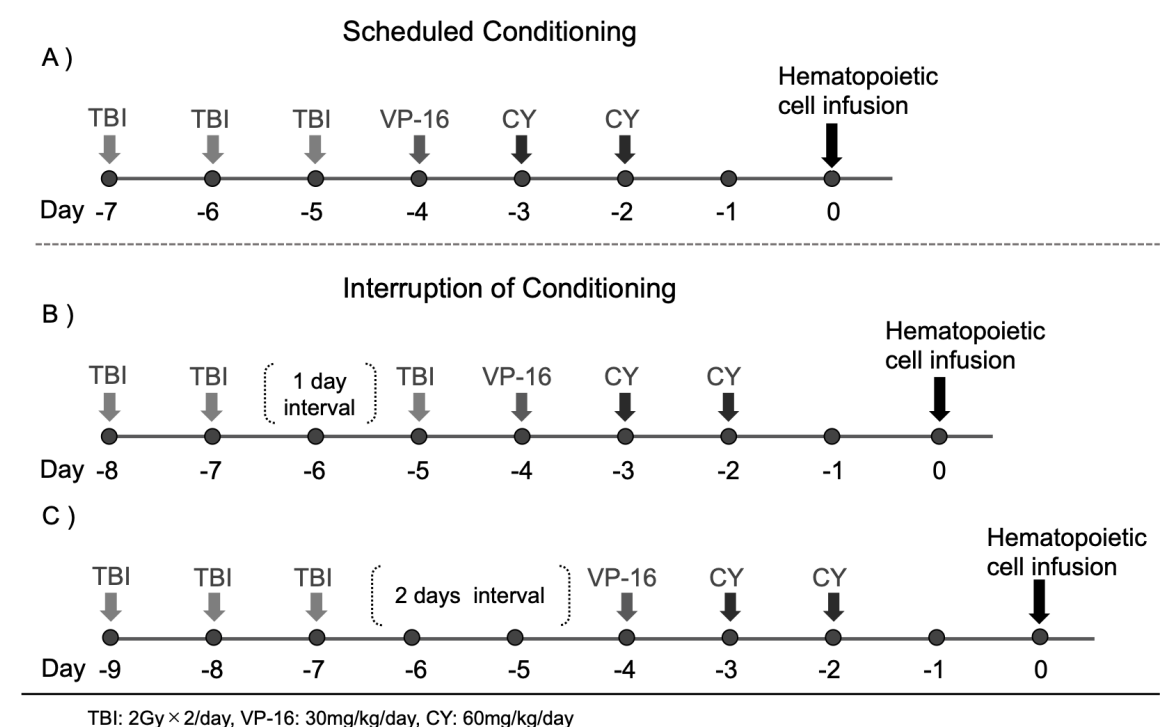


a

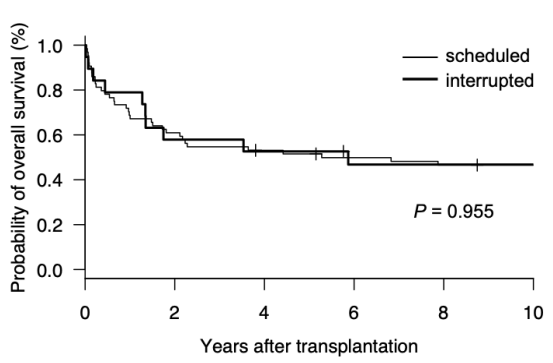

b

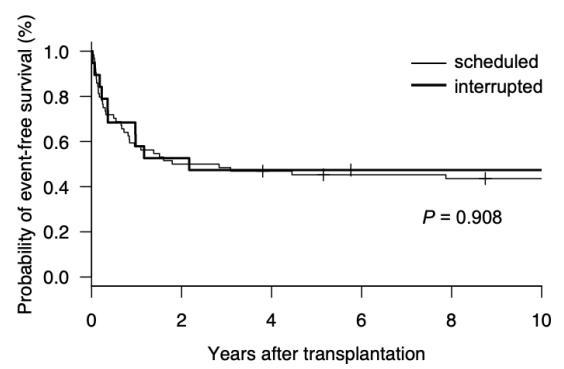

\section{Hosted file}

Table1.docx available at https://authorea.com/users/349376/articles/555621-one-or-twoday-intervals-in-conditioning-regimens-for-allo-hct-affect-chronic-graft-versus-hostdisease-but-not-other-clinical-outcomes

\section{Hosted file}

Table2.docx available at https://authorea.com/users/349376/articles/555621-one-or-twoday-intervals-in-conditioning-regimens-for-allo-hct-affect-chronic-graft-versus-hostdisease-but-not-other-clinical-outcomes

\section{Hosted file}

Table3.docx available at https://authorea.com/users/349376/articles/555621-one-or-twoday-intervals-in-conditioning-regimens-for-allo-hct-affect-chronic-graft-versus-hostdisease-but-not-other-clinical-outcomes

\section{Hosted file}

Table4.docx available at https://authorea.com/users/349376/articles/555621-one-or-twoday-intervals-in-conditioning-regimens-for-allo-hct-affect-chronic-graft-versus-hostdisease-but-not-other-clinical-outcomes 